\title{
THE TRANSGRESSIVE POTENTIAL OF THE 2014 CLEVELAND/AKRON GAY GAMES LEGACIES
}

\author{
NIGEL JARVIS \\ School of Sport and Service Management, University of Brighton, Eastbourne, UK
}

\begin{abstract}
Lesbian, gay, bisexual, transgender, and queer (LGBTQ) sport events potentially represent a significant transgressive and alternative space in the world of sport. There has been a scarcity of research on the full range of legacies that these types of medium-sized events can have, as previous studies focus on larger mega-sport events like the Olympics and/or economic and infrastructural aspects. This study evaluates the potential sociopolitical and sport legacies of the 2014 Gay Games held in Cleveland/Akron, based on interviews with 29 key stakeholders and complemented with conversations with 46 local residents. It demonstrates a range of positive sociopolitical and sport legacies were cited, although awareness of possible negative legacies and barriers also emerged. The discussions, centered on legacies, show the Games have symbolic significance for both the gay and wider community and accelerated the process of more accepting societal attitudes towards LGBTQ people. The conclusion discusses the somewhat qualified transgressive potential of the Games to challenge wider existing dominant heteronormative values in the local area.
\end{abstract}

\section{Key words: Gay Games; Sociopolitical and sport legacies; Event spectacles}

Introduction

There is considerable academic and applied event/destination management interest in critically investigating the legacies of sport events (Thomson, Schlenker, \& Schulenkorf, 2013), due not only to their prominence within the global arena, but their associated investment costs. Legacies are an integral part of the bidding process for hosting events, especially as the size of the occasion increases in scale. Naturally, bids tend to identify positive legacies that will be created, while negative ones are downplayed and may not emerge until later. The focus of much legacy research has been on largerscale events such as FIFA World Cups and Olympic Games (Kaplanidou, 2017; Leopkey \& Parent, 2012; 2015; Roche, 2003). However, smaller and less-known events can potentially have significant benefit for a destination (Shipway \& Kirkup, 2012).

Any type of event, even those away from a global media audience, has its own identity. Hence, it is 
important to investigate the broader impacts and resulting legacies of these types of events, beyond those economic and infrastructural elements (Ohman, Jones, \& Wilkes, 2006). Social, political, and environmental legacies are often ignored or felt by a number of stakeholders, such as local residents and businesses, community and cultural organizations, civic leaders, and sport groups. Any thorough assessment of an event needs to integrate and consider the full range of any type of legacy (Li \& McCabe, 2013). This article examines the dimensions of potential legacies associated with an alternative sport event, namely the 2014 Cleveland/ Akron Gay Games. Applying Roche’s (2000) dimensional typology of public events, the Games can be considered both as an international megaevent to its intended audience, while their citybased benefits, which are emphasized in its locale, may classify it as a hallmark event. However, the Games receive limited media coverage globally, which underpins Roche's typology. Thus, for this article, the Gay Games in Cleveland are considered a medium-sized event. Either way, for both the host city and the participants, the Gay Games are a significant special event with a multitude of shortand long-term social, cultural, political, and economic impacts and potential legacies.

The study investigates whether the types of legacies are similar to those associated with the better documented sport mega-events. It is also useful for those interested in competing discourses between professional and commercialized sport events and alternative grassroot formats aimed at inclusivity and challenging heteronormative values.

\section{The Legacy of Events}

Legacy is a much-used term among scholars as well as in the rhetoric promoted by destination organizations, event bidders, community groups, government officials, and politicians. There have been numerous studies focusing on event legacies dominated by sport, although other sectors like world expositions and business events have been researched. McGillivray, McPherson, and Carnicelli (2016) concluded legacy is one of the increasingly central themes explored by academics in the event field, although there appears to be some contested overlap with impact studies. Many conceptual articles exist on categorizing and identifying legacies; however, the literature reveals more empirical studies are needed, as suggested by authors such as Gammon (2015), Leopkey and Parent (2015), and Li and McCabe (2013), on simply identifying stakeholder's views on what they may actually be.

Legacy has been conceptualized as all planned and unplanned, hard and soft, positive and negative, tangible and intangible impacts, and/or structures created for, and by, an event, which remain longer than the event itself, irrespective of time and production and space (Gratton \& Preuss, 2008; Li \& McCabe, 2013; Sant, Mason, \& Hinch, 2013; Thomson et al., 2013). Considerable debate exists as to how to determine and measure a legacy ( $\mathrm{Li}$ \& McCabe, 2013; Preuss, 2007). Indeed, while mega-events are relatively short-lived entities they possess long-lived pre- and post- social dimensions (Roche, 2003). Thus, it is important to collect initial impressions of legacies because they lay the groundwork for which they can be measured against in the future.

Popular legacies created by sport events may include the much contested economic spend $(\mathrm{Li}$, Blake, \& Cooper, 2011), a supposed increase in sport participation rates (Grix, Brannagan, Wood, \& Wynne, 2017; Reis, Rodrigues de Sousa-Mast, \& Gurgel, 2014; Reis, Frawley, Hodgetts, Thomson, \& Hughes, 2017), and volunteer motivations (Aisbett, Randle, \& Kappelides, 2015; Blackman, Benson, \& Dickson, 2017), change in destination image (Li \& McCabe, 2013; Preuss, 2007), networking and making friends, sense of community pride, prestige and well-being (Foley, Edwards, \& Schlenker, 2014; Fredline, Jago, \& Deery, 2003; Preuss, 2007; Shipway \& Kirkup, 2012), and future event inspiration (Gursoy \& Kendall, 2006). The cultural legacies of people's collective memories of the lived experiences of the event are also important (Gruneau \& Horne, 2016). Positive social legacies may relate to strengthening cross-cultural partnerships, enacting agency, improving interethnic relationships, and instilling community values. Negative legacies are those that could lead to host/ visitor hostilities, a disruption to local lifestyles, and the use of events to legitimate unpopular decisions (Horne \& Manzenreiter, 2006; Leopkey \& Parent, 2012; Preuss, 2007). 
Legacies are further complicated because "destinations are notoriously difficult entities to manage due to the multiple stakeholder scenarios that underpin their development, management and marketing” (Shipway \& Fyall, 2012, p. 5). This is a key challenge for stakeholders from the tourism, event, and sport domains to achieve a successful occasion for their respective market. Each stakeholder may have a vested interest in promoting their own legacies. Concerns about hosting an event are often marginalized or downplayed in light of the greater good or enthusiasm it creates, often perpetuated by local politicians, the media, and middle-class consumers (Gruneau, 2002; Preuss, 2007). Further, while legacies may be planned as part of the inception of an event, over time changes in organizing committee personnel, wider shifting political agendas, acquiring sponsors, or developing news stories, may significantly alter those initially identified. Thus, legacies are often hard to achieve.

Drawing upon the work of Giddens (1990), events can be theorized as a mechanism to celebrate a collective consciousness to overcome negative feelings and affirm resident identities. They are seen to help enact social agency, although much of the past research on events and their potentially socially progressive agendas tend to downplay their contradictory features, especially with respect to aspects of injustice, inequality, social polarization, and domination (Gruneau \& Horne, 2016). On the other hand, Debord (1983) critiqued them, arguing the associated spectacle masks on-going issues for those socioeconomically disadvantaged. Regardless, festivals aimed at minorities or marginalized people are important symbolic occurrences for those taking part. For example, the role gay pride parades play in contested processes of social change surrounding sexual minorities is well documented (Kates \& Belk, 2001; Markwell \& Waitt, 2009), and they generally produce a range of positive legacies, outweighing negative ones that may emerge. Gay-related events, through playful and transgressive acts, help to question and challenge dominant heteronormative ideologies (Hetherington, 1997; Lee, Kim, \& Love, 2014; Waitt, 2003). They may change people's attitudes towards LGBTQ persons, although they may further embed stereotypes. Although Pride may be the typical cultural event associated with the LGBTQ community, less is known about other types of gatherings geared toward them. Therefore, it is worthwhile to explore how a gay sport festival may help reconfigure opinions of sexuality through the social connections made to bring the event together. Compared to Pride, extraordinary one-off cases like the Gay Games for host cities occur outside of other types of annual events, and thus are rarely experienced more than once in a lifetime for local stakeholders of any particular destination. The next section illuminates the Gay Games as an event and discusses the social significance of it as a sporting festival.

\section{The Gay Games Context}

The Gay Games, which began in 1982 and is held every 4 years like the Olympics, are arguably the most popular and globally recognized sport event for the LGBTQ community (Out in HK, 2017), although other competing events such as the Outgames have also emerged since 2006 (Symons, 2010). The mission of the Federation of Gay Games (FGG) (2018a), the body that oversees the movement, is "to promote equality through the organization of the premiere international LGBT and gay-friendly sports and cultural event known as the Gay Games.”

According to the FGG (2018b), the number of participants in the Gay Games has grown from an initial 1,300 athletes in San Francisco in 1982 to a peak of 13,000 in Amsterdam in 1998. Just under 8,000 attended Cleveland/Akron in 2014. Critics may point to this as a diminished demand although there may be simple explanations for the declining numbers. Olympic host cities and regions are often well-established tourist destinations prior to a bid (Sant et al., 2013), and this is true for all previous Gay Games host cities (e.g., New York in 1994, Sydney in 2002). Cleveland/Akron is not considered a major tourist nor gay destination. This may have affected athlete registration numbers. Further scrutiny reveals another complex issue at play. Traveling to compete in multiday events is expensive and many gay athletes, especially women, those from ethnic minorities and developing nations, find it difficult to take part. Indeed, much like the mainstream arena (King, Leonard, \& Kusz, 2007), the organization and participation of gay sport events tends to be dominated by a privileged white male middle class (Davidson, 2013). 
Past scholarly research on the Gay Games and LGBTQ sport events have focused on how they are seen as part of a general celebration and display of gay culture with a marked focus on making conspicuous lifestyle statements (Hargreaves, 2000). They also constitute a powerful and public reaction to homophobic discrimination and oppression in sport, and provide a safe space for participants. On this level then, participation in gay sport can be seen as having emancipatory power. The global growth and development of gay sports networks and events, like the Gay Games, have transformed the way gay athletes experience and understand sport (Pronger, 2000; Symons, 2010), although there are some critics (Davidson, 2014; Pronger, 2000; Sykes, 2006) of the role of these events who argue that they do not effectively challenge the prevalent heteronormativity of sport.

Symons' (2010) historiography of the Gay Games is useful for those wishing to develop a more comprehensive understanding of issues surrounding sport, gender, sexuality, queer, and feminist studies. Her work is also relevant to those interested in exploring the development of mega-sporting events and the competing discourses between commercialization and professional sport and grassroots sports models directed towards "sport for all" and inclusivity. However, her book fails to acknowledge the multiple legacies the events created, and creates a research gap.

\section{Cleveland/Akron 2014 Gay Games}

The Games were held in the Ohio cities of Akron and Cleveland between August 9-16. The Games organizers had hoped as many as 13,000 participants would take part, but around 8,000 took part. Athletes came from more than 50 countries. The Cleveland Foundation, a grantmaking charitable organization, was the Games' first ever presenting sponsor, meaning they provided financial support for contractual rights to the event, along with a diverse range of mainstream and local businesses, LGBT companies, and community institutions.

For some the fact that the 2014 Games were awarded to Cleveland/Akron in 2009 was surprising, as they are stereotypically seen as blue-collar cities in industrial decline, although Cleveland appears to be going through a strong period of urban regeneration. Events have the potential to show off a marginal city on a global scale (Horne \& Manzenreiter, 2006). Indeed, awarding the Games to the Cleveland area seems a brave choice because it is located in the heartland of mid-west America, perceived as a more conservative part of the nation. Stevenson, Rowe, and Markwell (2005) stated,

The coupling of the politics of sexuality and civic identity/economy is crucial because it is the promised economic benefits of the Gay Games that makes it attractive to cities that otherwise would almost certainly take little interest in a fringe and sometimes controversial event. (p. 453)

Indeed, Cleveland/Akron Games organizers' main aim for the Games was to help promote LGBT issues in the region, but also to create some visitor spending (Maag, 2009).

In the run up to the event, the cover story of Cleveland Magazine's 2014 August issue, headlined as “How Gay Are We?” focused on the inclusivity of the city. It concluded Cleveland requires further advancement on LGBT issues although compared to some other cities in Ohio it is seen as more progressive. The magazine hoped the Games would have some long-lasting legacies on the area, especially on the political, legal, and social fronts. However, what is lacking is further critical scholarly investigation focusing on the symbolic and transgressive potential nature of the event. A key legacy theme to thus explore is how the Gay Games contribute to reconfiguring attitudes about sexuality as part of wider sociopolitical agendas in Cleveland/Akron and beyond. Finally, it is imperative to explore what factors may inhibit any legacies from meeting their potential.

\section{Methodology}

As advocated by Leopkey and Parent (2015), it is important to gather insights from a range of diverse event stakeholders to determine potential legacies. This helps to enhance the empirical database, especially on smaller-sized events. Thus, it was crucial to reach out to sport groups, civic leaders, cultural organizations, volunteers, the event organizers, and sponsors to provide a holistic assessment of possible legacies. Further it was also deemed important to include the views of local residents, whose 
voices are often neglected in legacy research (Ma \& Kaplanidou, 2017).

A qualitative approach was undertaken in order to gain understanding of the potential legacies of the Gay Games in Cleveland/Akron and data were gathered in two strategic ways. First, a total of 29 stakeholders were formally interviewed in August 2014 (see Table 1). The interviews were conducted during the final days leading up to the event and while the week-long event took place. This happened because the researcher did not reside in North America and was at the event not only collecting data but taking part as an athlete. Thus, interviews took place during this strategic time. Further, the researcher was not familiar with the destination and thus needed some assistance to identify

Table 1

Stakeholder Profile

Type of Stakeholder/Organization

Name and Role(s) of Interview Participants

\section{LGBT organizations \\ 2014 Gay Games presented by The Cleveland Foundation \\ Lesbian Gay Bisexual Transgender Community Center of Greater Cleveland \\ Equality Ohio \\ Plexus Chamber of Commerce for the LGBT Community and Allies \\ Women's Happy Hour \\ Transgender Community \\ Diversity Center of Northeast Ohio \\ Community-based organizations (not LGBT specific) \\ AIDS Task Force of Greater Cleveland \\ Cleveland Neighborhood Progress}

\section{Civic leaders}

Cleveland City

\author{
Arts/cultural community \\ Cleveland Public Theatre \\ Philanthropy/funding community \\ Saint Luke's Foundation of Cleveland \\ The Foundation Center - Cleveland \\ The Cleveland Foundation \\ Business community \\ Consolidated Solutions \\ Tourism \\ Positively Cleveland (the Region's Convention and \\ Visitors Bureau) \\ Team Cleveland
}

\section{LGBT sport group representatives (reps)}

North Coast Bowling Association

North Coast Softball

Cleveland Aquatic Team

Lake Erie Volleyball Association

Cleveland Tennis

Shooters Pool (Billiards) League
Mary Zaller, Director of Development; Thomas Nobbe,

Executive Director

Phyllis Seven Harris, Executive Director

Alana Jochum, Northeast Ohio Coordinator

Michelle Tomallo, Board President, and Co-Founder and President of FIT Technologies; Todd Lloyd, Vice-President, and Financial Advisor, Wells Fargo

Luz Pellot, Co-Founder

Zoë Lapin, Activist

Christen DuVernay, Director of Programs

Tracey Jones, Executive Director; Garith Fulham, Director of Public Policy \& Advocacy/Director of Housing \& Homeless Services

Jeff Kipp, Director of Neighborhood Marketing; Colleen Gilson, Vice-President of Community Development Corporations

Joe Cimperman, Council Member, Ward 3; Valarie J. McCall, Chief of Government \& International Affairs

Raymond Bobgan, Executive Artistic Director

Nelson S. Beckford, Senior Program Officer for Strong Communities

Brian Schultz, Program Assistant

Kristi Andrasik, Program Officer

Wally Lanci, Corporate Counsel

David Gilbert, President and CEO, also for the Greater Cleveland Sports Commission

Don Hartman, Vice-President, (Softball, Bowling); Scott Swaggerty, President (Softball, Bowling, Volleyball, Billiards/Pool)

Eric Strong, President, also Director of annual GIFT Bowling Tournament

Jason Buffa, Commissioner

Julio Aponte, Swimmer/Team Representative

Justin Loew, Commissioner

Maurice (Moe) Cole, Vice-Commissioner

Mike Wunderle, Director 
key informants. Some stakeholders, like civic and business leaders, sponsors, and those from cultural organizations, were initially suggested by The Cleveland Foundation's Gay Games Program Officer, who helped publicize this research study and provided official consent for it to take place. Other stakeholders were identified through snowball sampling once some initial interviews took place. Sport representatives (reps) and tourism groups were identified by the researcher. The interviews took place at a variety of locations depending on the preference of the respondent. Some took place at their place of business, others in a public venue like a park or coffee shop, while others came to the researcher's hotel lobby. Interviews on average took between 25 to 45 minutes, enough time for a good level of reflection on the potential legacies of the Games.

Second, informal conversations were held with 46 local residents, such as taxi and bus drivers, police officers, shop assistants, customers and employees in restaurants, and people in the street when the opportunity arose. In most cases the locals were told of the academic nature of the questions being asked, and observations were recorded discreetly in a notebook immediately after. Conversations were initiated with those people who looked like they had some time to talk and were not distracted by other responsibilities. No names were asked for this part of the data collection process. This qualitative method was felt to better understand opinions, relationships, and connections attached to the event (Mackellar, 2013), of not only those more closely connected to the Games, such as stakeholders but also those citizens not associated with the event. Speaking with locals helped provide some supplementary evidence about awareness of the Games, although the main reflections on potential legacies came from the formal interviews.

Events are often criticized because they may be promoted and dominated by politicians, the media, or (white) middle-class consumers (Gruneau, 2002; Preuss, 2007). Hence, the formal interviews were conducted to strategically account for a broad and dynamic variety of communities and perspectives, such as Transgendered, African-American, Hispanic, and Caucasian, with a range of political, social, legal, and economic interests and sensitivities. It is important to account for those who are often socially marginalized in sport event legacy studies (Minnaert, 2012). This would hopefully reduce the ambiguity associated with legacies as stakeholders within the same event may have differing ideas and interpretations of what the term means (Gammon, 2015). Most interview partners volunteered their sexual identity through the natural course of the conversations, so the voices of both straight and LGBTQ citizens are reflected. By no means is this a fully representative sample of all stakeholders. Researchers sometimes rely on a small number of informants for a major part of their data, and even when these persons are purposefully selected and the data seem valid, there is no guarantee that these informants' experiences are typical (Maxwell, 1996). The 46 informal conversations held with other local residents were used to complement the stakeholder data to deflect some of the criticisms that legacy research tends to focus on them only. The timing of the data collection also has some limitation as it could have been gathered sometime soon after the event had concluded, but this was not possible due to the researcher's availability in the area. However, recommendations are made later about future data collection to address this issue.

The data were analyzed manually rather than using any qualitative analysis software programs in order to fragment and decontextualize the data (Weaver \& Atkinson, 1994). Analyzing the interview and conversational data was an iterative process in which the researcher moved back and forth to the data to contrast emerging initial themes (Matthews \& Ross, 2010; Silverman, 2011), before identifying overarching themes that were compared to the literature. Themes emerged from the formal interview prompts that were common to all participants, such as how they defined a legacy, before identifying particular legacies the Games may have on the area, and potential barriers to them coming to fruition. All 29 stakeholders, as well as the 46 locals, were also asked about their awareness of the Gay Games. These insights were used to assess the transgressive capacity of the event to contribute to a legacy of changing people's societal attitudes towards the LGBTQ community. All formal interview participants consented that their names could be used in the published article, and all but one agreed that the conversations were 
audio-recorded to allow a full accurate transcript. Names were not collected from the informal conversations with locals although their approximate age, as well as race and occupation, were noted whenever possible.

\section{Results and Discussion}

The stakeholder interviews revealed a range of potential legacies including ones related to tourism, arts, volunteering, economic spend, and event inspiration. However, due to word limits, this article focuses on the two most prominent types of legacies that emerged, namely the sociopolitical and sport aspects. The conversations with locals are used more to underpin the discussion section on the transgressive potential of the Games to enact social change.

The Potential Legacies of the 2014 Cleveland/Akron Gay Games

Respondents were first asked to self-identify any potential legacies before commenting on prompts from the researcher based on the literature. Due to the timing of the data collection many of the associated legacies were obviously not yet realized. "Community" was the term used most by stakeholders within the associated sociopolitical legacies, followed by the sport aspects.

\section{Sociopolitical Legacies}

The most prominent legacies to emerge were sociopolitical orientated, those often considered as less tangible. The Games allowed wider discussions and connections to be made with a diverse range of people and organizations. Valarie (Cleveland City Chief of Government and International Affairs) mentioned the "friendships created," cited by Foley et al. (2014), as a less considered legacy. For example, friendships were created by mechanisms such as training workshops with the police working with numerous LGBT organizations like Equality Ohio and the LGBT Center, and companies providing volunteers and engaging with the event volunteer coordinators. Mary (Director of Development Gay Games) said, "what these Games will do-have already done-for our cities and region is bringing us all together as a community-the awareness of LGBT people to the corporate community on a local level.”

Phyllis (LGBT Center), through her awareness and diversity training with organizations like the police and churches, believed a legacy was better communication with a diverse range of institutions. Connections made in the planning of the event helped to increase awareness of the LGBTQ community. Many positive legacies were consistently mentioned including: "increasing tolerance," "creating allies," "mobilizing the community," "making this a more inclusive place," "being a catalyst," "increasing pride," and "striving for equality."

Although connections were made to the wider straight community, perhaps more surprising was discord within the LGBTQ community. Zöe (Trans Activist), Michelle (Plexus/FIT sponsor), and Christin (Diversity Center) hoped the Games would make lesbians and gay men more welcoming to trans people. Phyllis believed the Games may help force gay men to think more about gender bias generally and attitudes toward women and bisexuals. She suggested this could occur through her Center holding community engagement events like guest speaker forums. Kristi (Cleveland Foundation) talked about having to reach out to groups who traditionally might not have been attracted to the Games such as a feminist women's group, “we stood up on the stage and said this is your chance to show the world you are part of the LGBT community in Cleveland . . . it is not just about young white men." Many stressed the importance that the Games reach out to marginalized people, not just the "gay" community, but those disadvantaged within that community, namely seniors, transgendered, women, young people, the homeless, and from Hispanic and African-American backgrounds. Both mainstream and gay sport are often critiqued because of the domination of white middle-class men (Davidson, 2013; King et al., 2007), and there was some sense that the Cleveland/Akron Games were similarly organized. These negative points demonstrate the challenges that may inhibit the potential positive legacies of the Games in the local area. Similarly, in other contexts, Waitt and Markwell (2006) noted the commercial gay tourism industry tends to portray the "gay tourist" within a very narrow framework, namely focusing on white 
affluent or middle-class men. Often gay tourism research fails to fully recognize women and other people in the LGBT market like seniors or transgendered persons.

Zöe felt the Games could be a great catalyst to help the community forge an identity and a sense of unity. Arguably, this was an optimistic view of unity as a key challenge for many events is to overcome stakeholders who may have vested interests in promoting their own legacies at the cost of others (Shipway \& Fyall, 2012). For example, the sport groups mostly focused on their sportingrelated needs in terms of better facilities and expanding participation numbers as opposed to wider sociopolitical aspects. Zöe's optimism was not universally felt. Kristi sensed some "apathy and lukewarm responses among people in the community" about the Games. Mary even believed some straight people were more excited about the Games coming compared to gay persons. Some felt the city was still divided, whether by the Cuyahoga River which creates east-west issues, or by deep-rooted tensions that exist between many communities. Both Tracey (AIDS Task Force) and Zöe were hopeful the Games may help overcome these geographic, ethnic, gender, class, or sexuality divisions. They, among others, suggested this could be achieved through the staging of future LGBTQ events in the area, which would enable people to continue to work together and help overcome the possibility that event organizers and stakeholders would go back to their "silos" once the Games were over.

There were several clear political legacies. Christen said, "Cleveland is a pretty progressive city but in terms of politics our state is in the bottom three for LGBTQ equality—so the Games coming here with this reputation was interesting." Many alluded to how the Games may provide leverage for concurrent gay legal battles in Ohio in 2014. For Joe (City Councilor) the political ramifications were clear:

The Games have always been about transformation ... as much as they are about the beauty of athleticism and health and collaboration and everything that sport brings . . . that we become a place of justice . . . not a place of fear and misinformation that we vote against equality ... the Games are a catalyst, the "redwood seeds" have been planted.
Many thought the Gay Games helped Cleveland win the bid to host the Republican Convention in 2016, considered a major political coup. Alana believed the Republican National Committee was coming "because they realize politically they need to embrace the LGBT community." This may inspire local people to host future events (Gursoy \& Kendall, 2006).

Preuss (2007) talked of legacies in terms of what would have happened if the event had not taken place. Were the Games the catalyst for increased acceptance and integration of the gay community and wider transgressive change? Most agreed it was; however, many felt it was hard to measure. A few felt societal changes towards LGBTQ people were happening already, but most thought the Games had accelerated the process. Wally said, "I defy anybody to say that would have happened without the Games.” Certainly, the Games were hoped to act as a catalyst for politicians to bring about legal change.

\section{Sport Legacies}

The second most mentioned type of legacy was related to sport, although nonsport stakeholders tended to not consider them. However, among the eight LGBT sport reps, in addition to David, who also represented the Cleveland Sports Commission in conjunction with his lead tourism commissioner role, the sport legacies were not surprisingly a clear focus. Beside wider sociopolitical aspects, conversations with these individuals related to how the Games affected their membership and attracted athletes from some traditionally socially marginalized groups.

Scott (Team Cleveland) hoped sport groups in the area would "see a $10 \%$ increase in numbers—20\% would be awesome.” Some groups saw participation numbers increase in the years leading up to the Games because people wanted to compete in those medal events and improve their athletic skills. Eric (Bowling) believed 5\%-10\% more people have joined the league in the past 2 years, while Jason (Softball) said the number of teams grew from 15 to 19. Justin (Volleyball) hoped to grow by $10 \%$, although Mike (Billiards) and Julio (Swimming) had not seen any growth. Most mentioned the gay sport scene in the local area 
tended to be dominated by white males, as are most sport networks (Davidson, 2013). However, some sport reps felt there had been more lesbians participating. Others saw some younger people (21 years and under) taking part. Gay youth are traditionally a difficult cohort to attract to sport. However, Scott warned "we are trying to reach out to the younger generation because we are all becoming dinosaurs. Once we are gone, if we don't have younger people on board, our sports leagues die.”

Reps noticed there were some transgendered athletes taking part in their leagues, with one team made up entirely of trans people. All ethnic minorities seemed to be represented but officials did not know if they were statistically underrepresented. Phyllis discussed her involvement in a women's softball team organized specifically for the Games, "it is amazing because we have people on our team, people of color. We have at least two who are over 55 . . . our manager is an out trans individual." Despite this she very was concerned about lack of participation among sport among minorities. Still, this shows that sport can be a powerful tool to bring together diverse types of people despite it being dominated by white men.

The sport reps had a difficult time agreeing if the growth in numbers were a natural occurrence or a direct result of the Games, cited by Reis et al. (2014, 2017) and Grix et al. (2017) as also a muchcontested legacy of larger mega-events. Thomas (Executive Director Gay Games) and David (Positively Cleveland) believed a legacy was a more solid infrastructure of LGBT sport organizations in the region, which hopefully will lead to both LGBT and mainstream sport tournaments being held in Cleveland/Akron. Most agreed the Games had increased awareness of LGBT sport groups in the area not only among gay people but also heterosexuals. Moe (Tennis) said a straight person heard of him playing softball and said, "I don't mean to be offensive but I didn’t know gay people played ball and some of them were really good.” This helps challenge pervasive stereotypes of gays in sport. It also blurs the traditional straight/gay sport binary (Jarvis, 2015). Organizers of the LGBT leagues said there had been some further integration into mainstream sporting spheres and venues. Mike said they had to play billiards in some straight bars because of the lack of gay venues and were welcomed by owners and patrons. Many of the venues used for the Gay Games were high profile spaces, such as Quicken Loans Arena, and the PGA Firestone golf course. The simple use and appropriation of these sites, normally representing heteronormative or traditional masculine sporting ideologies (Krane, 2001), could be seen as helping to legitimate LGBTQ people's experience and contest dominant sporting values. In summary, the sport reps had a very positive view of potential legacies; however, their thoughts seemed anecdotal with little evidence.

\section{Negative Legacies and Barriers}

Stakeholders identified a range of legacies and for most they were skewed strongly positive. Brian (Foundation Center) immediately was more balanced, "it can go either way for a legacy ... there aren’t always good legacies.” Thus, the next part of the interviews focused on negatives aspects and/or barriers that may inhibit the legacies from meeting their potential. Michelle (Plexus/FIT sponsor) was worried the Games potentially had "started on the wrong foot" with a smaller number of participants $(8,000)$ compared to previous Games and may already be a negative legacy.

A key concern was related to loss of "momentum" or "political will" once the Games finished. Joe, the local politician, thought "there is a chance we could be comfortable again in our quiet allyness.” Jason (Softball) worried complacency was possible and had spoken to some people in the LGBT community who did not know of the Gay Games. Sport does not play an important part in the lives of many in the gay community (Waitt, 2003). For these people, the Games are likely to have a diminished legacy. Similarly, Kristi thought some people cannot relate to the event and said, “I don’t see my face, it doesn't include me ... folks who saw it as being something for middle-class white men. It is an expensive event . . . it takes a certain amount of privilege to take part.”

Cost of joining local leagues, as well as registering for the Gay Games, was seen as a barrier for many, a much-cited issue within the sport participation literature (Davidson, 2013; King et al., 2007), as it affects the socioeconomically disadvantaged. Luz (Women’s Happy Hour) hoped more women 
would participate in the Games or other sports, while Jason said softball was costly, especially for youth, the poor, and some minorities. Many said if one simply cannot get people involved in sport because of cost, the legacy is lessened. The majority thought key stakeholders could potentially go "back to their silos," while Phyllis felt the pressure and stressed the importance that her organization has in making sure legacies happen, but also that it needs to be shared between a number of different types of institutions.

Mary (Director of Development Gay Games) wondered if a downside would be a lost gay identity, as "we are becoming more mainstream and our culture is going to be lost through working with straight people." For queer theorists (Caudwell, 2006; Davidson, 2013; Sykes, 2006) the erasure of, or normalization of, a marginal sexual identity is a major concern. A couple feared the Games would further embed stereotypes, and one interview partner recalled he had heard some business leaders saying gay sport was "people in tutus playing sport ... . but they quickly changed their minds and attitudes.” This suggests the Games were successful at least in this case of actually changing people's misconceptions. Zöe, the trans activist, looked more inwardly, "the Cleveland LGBTQ community needs to get over itself and celebrate each other's differences."

While the formal interviews with stakeholders focused on legacies and barriers, conversations with 46 locals explored their awareness of the Games. The majority were knowledgeable to some degree because they had seen media coverage on local television and news. Over half mentioned the extra spending the event would create. A young white bartender said he only learned of the Games two months prior "they are not on my radar. . . I have gay friends and generally know what's going on but I don't know what they are about.” A white middle-aged police officer said, "I don't know anything about the Games ... my other officers don't know about it, they are not talking about them.” An older African-American male, riding on the train commented, "Yeah I know the Games are here but don't know anything about them. I didn't know how big they were . . . my friends aren't talking about them." An older white waitress said, "I don't know what they are about but I don't care, live your life . . . the Games are about gay equality and marriage and that is great.” A few locals discussed some positive issues beyond their awareness, with some commenting on the fact that the event would be "great" for Cleveland, and "bring people together to celebrate," while one young African-American father was looking forward to taking his young daughter downtown to "see all the parades." None of the locals discussed any negative barriers related to the event but ad-hoc conservations did not really allow them to go into much reflection in this direction.

There appeared to be a clear relationship between age and awareness, with younger locals being much more knowledgeable about the Gay Games. A young white female shop assistant said, "I forgot to wear my wristband today in support ... yeah lots of my crowd are talking about the Games ... we all know the Games are here and some of my friends are volunteering.” A couple of young female volunteers, who both said they were straight, were really excited to learn about the Games. A couple of young gay African-American men revealed they knew of the Games but did not have much of a connection to sport and that the cost was prohibitive. An older black woman in the Ohio City neighborhood, and actively involved in community issues, said "some African-Americans feel they haven't been represented by the Games but they generally know they are here and have no negative attitudes towards them, they just don't know what they represent." A young Hispanic waiter "Yeah I know the Games are here ... don't know much about them but one of my friends is gay and that is cool.” In summary, locals demonstrated a somewhat ambivalent attitude toward the Games being in Akron/ Cleveland.

Although all the stakeholders considered the legacies created by the Games on a macrolevel, few reflected on whether they were affected on a personal level. Well over half of the stakeholders (19), regardless of sexuality, did not know much about the Gay Games movement before the awarding of the event in 2009. However, most became knowledgeable about the history and mission of the Games and what they could mean to people and the host region. Conversations with 46 locals also revealed the majority (71\%) did not know much about the Cleveland Gay Games nor the wider 
Games movement, but most knew superficially the Games were occurring because of local media.

What the Games did for all stakeholders, from their initial involvement, was to start conversations. Friends and family members, coworkers, and the business community started to ask questions about the nature of the event, what they would mean to the gay community and wider society. The Games seemed to help break down barriers within families. One stakeholder said,

Definitely in terms of my family they are asking a lot more questions . . . they tend to be pretty conservative Republicans and they are not really into social justice issues as much . . . my partner has an incredibly conservative sister and she came to the opening ceremonies. It was great to see . . . you would never have guessed she would be interested in doing something like that.

\section{Alana (Equality Ohio) recalled,}

My husband and I found out they were coming ... we looked at each other and said "Oh my god, this is the first we have heard about this, we need to round up everybody that we know so that Cleveland doesn't have a pathetic showing." So we spread the word as much as we could among our friends ... . we are so proud of our city.

These comments demonstrate a range of positive social aspects on the personal level, which start to overlap with the previously mentioned community-level issues, related to strengthening cross-cultural partnerships, event inspiration, networking, and community pride. Many talked of the friendships created. The literature tends to consider these aspects as less-tangible elements (Foley et al., 2014; Fredline et al., 2003; Leopkey \& Parent, 2012; Li \& McCabe, 2013; Preuss, 2007). For a few, the Games had deep personal meaning. For Wally (Consolidated Solutions), the Gay Games were part of the coming out process as they helped him reconcile fears over his sexual identity and exposed the considerable resources in the community, "I didn't know that the LGBT Centre existed . . . [before I came out] there was a lot of feeling alone and just scared." This has resonance to Giddens (1990), who theorized events as a tool to overcome negative feelings and affirm identities.

\author{
Discussion and Conclusions \\ About the Transgressive Potential \\ of the Gay Games Legacies
}

The empirical data identify the interconnections created and the complex dimensions (Leopkey \& Parent, 2012, 2015) associated with potential legacies of a less-known alternative event like the Gay Games. Shipway and Kirkup (2012) suggested smaller or medium-sized events can have a greater benefit for a host compared to those related to mega-sport events. This appears to be the case in Cleveland/Akron. This research provides a thorough assessment of a range of possible aspects beyond the traditional focus on economic or infrastructural legacies created by larger sport events. Although a range of sociopolitical and sport legacies, in addition to others, were created on a macrolevel, it is important to remember how the Games may also have left a personal positive legacy on each stakeholder and some of the local residents who took part in volunteering or interacted with athletes and visitors. For many, the Games left a potential mark on their individual social, political, and sporting capital, but also on their collective memories and lived experiences, cited by Gruneau and Horne (2016) as important.

Overall, the wider legacies skewed very positively, although some challenging barriers existed that may inhibit them from reaching their full potential. The interviews with stakeholders revealed a diverse number of potential legacies often cited in the literature, from fairly standard tangible aspects (e.g., increased sport participation) to the more often mentioned intangible legacies (e.g., increasing community pride and confidence, networking). It also shed light on legacies not considered before such as the intangible social issues like increasing awareness to community resources and inspiring new talent to emerge to carry on the potential legacies or become involved in bidding to host future events. Respondents tended to categorize the legacies in terms of tangibility or positivity/negativity quite often, although the other conceptual terms cited in the literature such as hard/soft, planned/ unplanned were not explicitly used.

Although a range of positive legacies were identified, one must remember the 29 stakeholders interviewed may have a vested interest in promoting 
them at the cost of others. Further, as pointed out by Gruneau (2002) and Preuss (2007), concerns about hosting an event are often marginalized or downplayed for the greater good. This project has given equal voice to negative and positive aspects, exposing community anxieties and tensions, thus providing a balanced and revealing assessment, which Li and McCabe (2013) stated is crucial for event legacy research. Generally, all the interviews were largely positive, and in a few cases ambivalent, but the Games' legacy in encouraging acceptance is one that cannot be discussed without knowing the types, and possibly extent, of existing negative sentiments. The currentlymentioned negative feelings were largely related to event size and a lack of diversity (racial, age, economic, gender, etc.) among Games participants, but these do not represent the larger issues of LGBT equality as championed by the event organizers. Further, the positive legacies should be tempered by the simple lack of awareness of the Gay Games movement among a majority of the local residents, who although supportive, did not reflect on wider sociopolitical or sporting aspects.

Significantly, Preuss (2007) referred to what would have happened if the event had not taken place. Thus, some thoughts are raised as to whether the Gay Games is a catalyst for legacies to emerge and transformations, such as sociopolitical attitudinal change toward LGBT people, taking place in the Cleveland/Akron. Regardless of the event, wider societal attitudes toward sexual minorities are moving in a positive direction in most developed nations. Certainly, the vast majority of those interviewed believed the Games accelerated the process of change related to sociopolitical legacies such as increasing awareness of the LGBTQ community, providing leverage for related legal battles in Ohio, and creating connections and alliances between gay and straight people and institutions. The sporting context further helps speed up the integration of gay people into the wider community, as people learn about the sport needs and issues associated with a sexual minority group. This also helps break down long-held stereotypes about LGBTQ people in general and specifically athletes. Although this points to a largely positive position, some challenges remain, such as a loss of momentum once the Games finish, apathy, cost and funding, or people becoming comfortable with the work being completed and going back to their "silos." Further, how can wider change or acceptance of sexual diversity occur when a large proportion of local residents are not fully aware of the event and its mission?

A key challenge in the study of legacies is how to measure their impact (Li \& McCabe, 2013) and at what point does one gauge them because they have considerable pre- and postsocial dimensions (Roche, 2003). Such considerations are relevant to Cleveland/Akron. As Valarie (Cleveland City Chief of Government and International Affairs) says "the simple fact that the Games were in Cleveland is a legacy. We hosted the Games ... . but I'd like to attend a Gay Games in 20 years now and hear people still talking about Cleveland." However, she and many others thought the biggest "takeaway" was intangible, something hard to measure, and not necessarily visible. Legacies can be unpredictable. Either way, many felt the event was a profound history-marking occurrence, helping to "rebuild our city," although whether it is forging a new identity (Stevenson et al., 2005) remains unclear.

As a phenomenon, the Gay Games has potential for much symbolic significance. But do they have the transgressive ability to overcome negative feelings about the LGBTQ community from the outside or even within it? As Giddens (1990) stated, events, such as the Gay Games, have the power to affirm local resident identities. Debord (1983) was much more critical, suggesting event spectacles conceal enduring issues affecting socioeconomically marginalized people. The answer appears to be a qualified yes - the Gay Games can be seen as a disruptive and playful platform to challenge and question dominant heteronormative ideologies (Hetherington, 1997; Lee et al., 2014; Waitt, 2003), change attitudes toward LGBTQ people, and raise awareness about wider gay-related legal battles. Similarly related to sport, the Games can help contest and undermine prevailing heteronormative and masculine values (see for example Anderson, 2009; Caudwell, 2006; Connell, 1995). Perhaps these are the most important legacies, rooted in sociocultural and political discourses, and not just on the more traditional economic indicators. As noted, new narratives have been created in Cleveland/Akron 
around configurations of sexuality, and while the Games can contribute to tackling some immediate issues, many more remain to be addressed. These include changing attitudes among some within the gay community and meeting the sociopolitical and/ or sporting needs of those marginalized still within the LGBTQ community, namely youth, seniors, trans, the homeless, from ethnic minorities, and to some extent women and even bisexuals. The voices heard in this study did not want the Gay Games to be the endpoint, that everything is fine, when many concerns persist. As Alana reminded us, "we need to have a healthy balance, we need to take the excitement that we have now and channel it into work that still needs to be done."

Preuss (2007) talked about the importance of momentum created by an event, often built on emotion. The literature, grounded mainly in megasports, says events give politicians and other stakeholders a vision. Citizens become emotionally involved. The private and corporate sectors are inspired by welcoming an extraordinary and widely-known event. Although this may be true for the Olympics, is it the same for the Gay Games in Cleveland/Akron? Again, the answer is a qualified yes, as concerns about a loss of momentum is a challenge that may prevent the full leverage potential of identified legacies coming true.

Tracey (AIDS Task Force) said "we need to figure out how to make the Gay Games' legacy a living, breathing experience." Events make cities evaluate themselves and help strategically plan for the future. Some initiatives are promising so the transforming process can continue. Plexus, the "LGBT allied" arm of the Chamber of Commerce, has hired a strategist to further economic legacy work and to oversee continued collaboration of businesses with the gay community. Plexus, the LGBT Center of Greater Cleveland, Neighborhood Progress, Equality Ohio, and the Community AIDS Network and Akron Pride Initiative have established an online platform where participants of the Games can remain connected and communicate about their collective experiences and memories. Various funds and resources have been donated and awarded so future legacy work continues. However, some may see this as a fragmented approach and what is needed may require some type of legacy committee, although what form that takes and resource funding aspects would need to be determined. A legacy committee could also focus some funding toward helping those LGBTQ people in the local area who felt marginalized (seniors, transgendered, women, young people, the homeless, Hispanic, and African-American) to take part in sport. This could be done by marketing campaigns to raise awareness of opportunities to subsidizing registration fees or equipment costs. This could aid in making the gay community more inclusive and diverse and lessening some of the negative issues that emerged in the study.

Finally, more longitudinal work is clearly needed. This study has provided insight into initial impressions of potential sociopolitical and sport legacies associated with the Cleveland/Akron Gay Games. This lays the groundwork for monitoring and measurement in future, whether 2 or 5 years or even longer. Thus, it is suggested stakeholders and local residents are interviewed again so they may reflect on and self-assess any legacies initially identified. For example, sport reps provided anecdotal evidence of participation rates so future data collection could identify actual numbers overall but also by age, gender, ethnic background, etc. Interviews can further explore the continued transgressive power of the Games in challenging societal attitudes. This will aid in understanding whether promised legacies are achieved, instilling trust (Gammon, 2015) in the power of alternative events to enact real sociopolitical change rather than being a one-off short-term spectacle as critiqued by Debord (1983).

\section{References}

Aisbett, L., Randle, E., \& Kappelides, P. (2015). Future volunteer intentions at a major sport event. Annals of Leisure Research, 18(4), 491-509.

Anderson, E. (2009). Inclusive masculinity: The changing nature of masculinities. New York, NY: Routledge.

Blackman, D., Benson, A., \& Dickson, T. (2017). Enabling event volunteer legacies: A knowledge management perspective. Event Management, 21(3), 233-250.

Caudwell, J. (Ed.). (2006). Sport, sexualities and queer/ theory. London: Routledge.

Connell, R. W. (1995). Masculinities. Cambridge, UK: Polity Press.

Davidson, J. (2013). Sporting homonationalisms: Sexual exceptionalism, queer privilege, and the 21st century international lesbian and gay sport movement. Sociology of Sport Journal, 30, 57-82. 
Davidson, J. (2014). Racism against the abnormal? The twentieth century Gay Games, biopower and the emergence of homonational sport. Leisure Studies, 33(4), 357-378.

Debord, G. (1983). Society of the spectacle. London, UK: Rebel Press.

Federation of Gay Games. (2018a). Mission, vision and values. Retrieved from https://gaygames.org/Mission\&-Vision

Federation of Gay Games. (2018b). History of the FGG and the Gay Games. Retrieved from https://gaygames.org/ History

Foley, C., Edwards, D., \& Schlenker, K. (2014). Business events and friendship: Leveraging the sociable legacies. Event Management, 18, 53-64.

Fredline, L., Jago, L., \& Deery, M. (2003). The development of a generic scale to measure the social impacts of events. Event Management, 8(1), 23-37.

Gammon, S. (2015). A legacy of legacies: limitations of the future perfect. Annals of Leisure Research, 18(4), 445-449.

Giddens, A. (1990). The consequences of modernity. Cambridge, UK: Polity.

Gratton, C., \& Preuss, H. (2008). Maximising Olympic impacts by building up legacies. The International Journal of the History of Sport, 25, 1922-1938.

Grix, P., Brannagan, P.M., Wood, H., \& Wynne, C. (2017). State strategies for leveraging sports mega-events: Unpacking the concept of "legacy.” International Journal of Sport Policy and Politics, 9(2), 203-218.

Gruneau, R. (2002). Foreward. In M. Lowes (Ed.), Indy dreams and urban nightmares (pp. ix-xii). Toronto, Canada: Toronto University Press.

Gruneau, R., \& Horne, J. (Eds.). (2016). Mega-events and globalization: Capital and spectacle in a changing world order. Abingdon, UK: Routledge.

Gursoy, D., \& Kendall, K. (2006). Hosting mega-events modelling locals' support. Annals of Tourism Research, 33(3), 603-623.

Hargreaves, J. A. (2000). Heroines of sport: The politics of difference and identity. London, UK: Routledge.

Hetherington, K. (1997). The badlands of modernity: Heterotopia and social ordering. London, UK: Routledge.

Horne, J., \& Manzenreiter, W. (2006). An introduction to the sociology of sports mega-events. The Sociological Review, 54, 1-24.

Jarvis, N. (2015). The inclusive masculinities of heterosexual men within UK gay sport clubs. International Review for the Sociology of Sport, 50(3), 283-300.

Kaplanidou, K. (2017). Health-related attitudes and behaviors among Olympic host city residents from Atlanta, Sydney, Athens, and Beijing Olympic Games: Exploring potential legacies. Event Management, 21, 159-174.

Kates, S. M., \& Belk, R. W. (2001). The meanings of lesbian and gay pride day. Journal of Contemporary Ethnography, 30(4), 392-429.

King, C. R., Leonard, D. J., \& Kusz, K.W. (2007). White power and sport: An introduction, Journal of Sport and Social Issues, 31(3), 3-1.
Krane, V. (2001). We can be athletic and feminine, but do we want to? Challenging hegemonic femininity in women's sport. Quest, 53(1), 115-133.

Lee, S., Kim, S., \& Love, A. (2014). Coverage of the Gay Games from 1980-2012 in U.S. newspapers: An analysis of newspaper article framing. Journal of Sport Management, 28(2), 176-188.

Leopkey, B., \& Parent, M. M. (2012). Olympic Games legacy: From general benefits to sustainable long-term legacy. International Journal of the History of Sport, 29(6), 924-943.

Leopkey, B., \& Parent, M. M. (2015). Stakeholder perspectives regarding the governance of legacy at the Olympic Games. Annals of Leisure Research, 18(4), 528-548.

Li, S. N., Blake, A., \& Cooper, C. (2011). Modelling the economic impact of international tourism on the Chinese economy: A CGE analysis of the Beijing 2008 Olympics. Tourism Economics, 17(2), 279-303.

Li, S. N., \& McCabe, S. (2013). Measuring the socioeconomic legacies of mega-events: Concepts, propositions and indicators. International Journal of Tourism Research, 15, 388-402.

Ma, S. C. A., \& Kaplanidou, K. (2017). Legacy perceptions among host Tour de Taiwan residents: The mediating effect of quality of life. Leisure Studies, 36(3), 423-437.

Maag, C. (2009). Forget Chicago. Cleveland gets the gay games. Retrieved from http://content.time.com/time/ nation/article/0,8599,1927211,00.html

Mackellar, J. (2013). Participant observation at events: Theory, practice and potential. International Journal of Event and Festival Management, 4(1), 56-65.

Markwell, K., \& Waitt, G. (2009). Festivals, space and sexuality: Gay Pride in Australia. Tourism Geographies, 11(2), 143-168.

Matthews, B., \& Ross, L. (2010). Research methods: A practical guide for the social sciences. Harlow, UK: Pearson Education Ltd.

Maxwell, J. A. (1996). Qualitative research design: An interactive approach. London, UK: Sage Publications.

McGillivray, D., McPherson, G., \& Carnicelli, S. (2016). Sporting and cultural events: Contested legacies. Annals of Leisure Research, 18(4), 441-444.

Minnaert, L. (2012). An Olympic legacy for all? The non-infrastructural outcomes of the Olympic Games for socially excluded groups. Tourism Management, 33(2), 361-370.

Ohmann, S., Jones, I., \& Wilkes, K. (2006). The perceived social impacts of the 2006 World Cup on Munich residents. Journal of Sport and Tourism, 11(2), 129-152.

Out in HK. (2017). What are the Gay Games? Retrieved from https://www.gaygameshk2022.com/about-gay-games

Preuss, H. (2007). The conceptualisation and measurement of mega sport legacies. Journal of Sport and Tourism, 12(3/4), 207-228.

Pronger, B. (2000). Homosexuality and sport: Who's winning? In J. McKay, M. Messner, \& D. Sabo (Eds.), Masculinities, gender relations, and sport (pp. 222-244). London, UK: Sage Publications. 
Reis, A. C., Frawley, S., Hodgetts, D., Thomson, A., \& Hughes, K. (2017). Sport participation legacy and the Olympic Games: The case of Sydney 2000, London 2012, and Rio 2016. Event Management, 21(2), 139-158.

Reis, A. C., Rodrigues de Sousa-Mast, F., \& Gurgel, L. A. (2014). Rio 2016 and the sport participation legacies. Leisure Studies, 33(5), 437-453.

Roche, M. (2000). Mega-events and modernity: Olympics and expos in the growth of global culture. London, UK: Routledge.

Roche, M. (2003). Mega-events, time and modernity. Time and Society, 12(1), 99-126.

Sant, S-L., Mason, D. S., \& Hinch, T. D. (2013). Conceptualising Olympic tourism legacy: Destination marketing organisations and Vancouver 2010. Journal of Sport and Tourism, 18(4), 287-312.

Shipway, R., \& Fyall, A. (Eds.). (2012). International sports events: Impacts, experiences and identities. London, UK: Routledge.

Shipway, R., \& Kirkup, N. (2012). Guest editorial: The impacts of legacies of sports events. International Journal of Event and Festival Management, 3(3), 1-5.
Silverman, D. (2011). Interpreting qualitative data (4th ed.). London, UK: Sage Publications.

Stevenson, D., Rowe, D., \& Markwell, K. (2005). Explorations in "event ecology": The case of the International Gay Games. Social Identities, 11(5), 447-465.

Sykes, H. (2006). Queering theories of sexuality in sport studies. In J. Caudwell (Ed.), Sport, sexualities and queer/theory (pp. 13-32). London, UK: Routledge.

Symons, C. (2010). The Gay Games: A history. London, UK: Routledge.

Thomson, A., Schlenker, K., \& Schulenkorf, N. (2013). Conceptualizing sport event legacy. Event Management, 17, 111-122.

Waitt, G. (2003). Gay Games: Performing “community” out from the closet of the locker room. Society and Cultural Geography, 4(2), 167-183.

Waitt, G., \& Markwell, G. (2006). Gay tourism: Culture and context. Binghamton, NY: Haworth Press.

Weaver, A., \& Atkinson, P. (1994). Microcomputing and qualitative data analysis. Aldershot, UK: Avebury. 